\title{
Assessment of the complications after percutaneous fixation with cannulated cancecellous screws among the cases of tibial plateau fractures in a tertiary healthcare institute: a cross sectional study
}

\author{
Joti P. Bagul ${ }^{1 *}$, Pankaj P. Dole ${ }^{2}$ \\ ${ }^{1}$ Department of Orthopedics, Shri Bhausaheb Hire Government Medical College and Hospital, Dhule, Maharashtra, \\ India \\ ${ }^{2}$ Department of Orthopedics, Amina Hospital, Ajman, UAE \\ Received: 17 April 2019 \\ Revised: 02 January 2020 \\ Accepted: 04 January 2020 \\ *Correspondence: \\ Dr. Joti P. Bagul, \\ E-mail: researchexpert3@gmail.com \\ Copyright: ( ) the author(s), publisher and licensee Medip Academy. This is an open-access article distributed under \\ the terms of the Creative Commons Attribution Non-Commercial License, which permits unrestricted non-commercial \\ use, distribution, and reproduction in any medium, provided the original work is properly cited.
}

\section{ABSTRACT}

Background: Fractures in the tibial plateau were first defined as car bumper fractures. Tibial plateau fractures are a diverse group of fractures that reflect a wide range of intensity, ranging from simple accidents to intricate fracture trends that test even the most qualified surgeons. The present study was conducted to study the result of minimally invasive technique for tibial plateau fractures by percutaneous fixation with cannulated cancellous screws and to study complications associated with it in a tertiary care center.

Methods: It was a cross sectional study conducted among 13 patients with tibial plateau fractures during January 2016 to December 2016 admitted under department of orthopedics in a tertiary healthcare institute in northern Maharashtra. The criteria for selection of a case were a fracture of tibial plateau (Shatzker's type I to type IV) with displacement or depression more than $8 \mathrm{~mm}$.

Results: One patient (7\%) had compartment syndrome at the time of presentation. No patient in our series had early postoperative complication. One patient developed knee joint pain 16 months after operation due to early osteoartgritic changes.

Conclusions: There was no early complication related to surgery like superficial or deep infection, damage to neurovascular structures, etc. Ten patients (76\%) achieved full range of knee motion within 3 months after operation. All the fractures were united within 14 weeks duration.

Keywords: Tibial plateau fractures, Shatzker's classification, Management, Complications

\section{INTRODUCTION}

Fractures in the tibial plateau were first identified as car bumper fractures. ${ }^{1}$ Tibial plateau fractures are a diverse group of fractures that reflect a wide range of intensity, ranging from simple accidents to intricate fracture trends that test even the most qualified surgeons. ${ }^{2}$

Tibial plateau fractures are one of the most frequent intraarticular fractures arising from indirect coronal or direct axial compressive forces. Fractures of the tibial plateau constitute $1 \%$ of all fractures and $8 \%$ of all fractures in the elderly. ${ }^{3}$

Such fractures include many and different fracture types including medial condyle (10 to 23 per cent), lateral condyle (55 to 70 per cent) or both (11 to 30 per cent) of varying degrees of joint compression and displacement. 
In the event of inadequate reconstruction of the surface of the base and the backbone of the hip, such fractures may lead to the development of premature osteoarthritis, ligament injury, chronic pain and disability. ${ }^{4}$ Tibial plateau fractures may be caused by meniscal and ligamentous knee injuries. ${ }^{5}$

Initial damage detection, rehabilitation and prognosis estimation, orthopedic surgeons commonly use the Schatzker classification system, which distinguishes tibial plateau fractures into six forms. Each increasing numeric category specifies an increased level of energy given to the bone, thus increasing the severity of fractures. ${ }^{5}$

The first four are unicondylar, and the V and VI are bicondylar. That fracture pattern in the Schatzker hierarchy helps direct orthopedic surgeons to follow appropriate treatment modality. ${ }^{6}$

At present, intra-articular lesions are best treated with meticulous anatomical reduction and rigid fixation of the joint fragments using internal fixation techniques. However, this approach may also lead to problems with soft tissues and failures in fixation.

Poorly placed incisions and severe dissection continue to cause excessive poor tissue necrosis and serious wound infections. Rescue with local or free flap is possible; knee operation and gestures may be impaired. Such issues have been eliminated and principles of bone reduction such as conditional reduction and biological fixation have been maintained ${ }^{7}$

Such minimally invasive procedures are being developed and used in all fields of surgery. The effects of decreased morbidity and shortened hospital stay are well known. Closed reduction and percutaneous pinning have been used in the diagnosis of selective fractures, in particular intracapsular hip fractures, and arthroscopy is a basic tool in the treatment of all forms of internal disorders of the knee and is used in many other joints.

The use of combination of these two techniques in the treatment of tibial plateau fractures in not new. ${ }^{8}$

The present study was conducted to evaluate the effect of a minimally invasive procedure for tibial plateau fractures through percutaneous fixation with cannulated cancer screws and to study the risks connected with it in a tertiary care centre.

\section{METHODS}

It was a cross sectional study conducted among 13 patients with tibial plateau fractures during January 2016 to December 2016 admitted under department of orthopedics in a tertiary healthcare institute in northern Maharashtra. The criteria for selection of a case were a fracture of tibial plateau (Shatzker's type I to type IV) with displacement or depression more than $8 \mathrm{~mm}$.

In the present study, all the patients were treated with closed reduction and percutaneous fixation with cannullated cancellous screws.

Cancellous bone screws are made from stainless steel and characterized by relatively thin core and wide and deep threads. These characteristics give such a screw considerably increase holding power in fine trabecular bone of metapyseal and epiphyseal region.

Table 1: Description of the instruments used.

\begin{tabular}{|lll|}
\hline Screw deseription & Dimensions available $(\mathrm{mm})$ & Length available $(\mathrm{mm})$ \\
$\begin{array}{l}\text { Partially threaded cannulated } \\
\text { cancellous screw }\end{array}$ & $\begin{array}{l}6.5 \mathrm{~mm} \text { large fragment and } 4.0 \mathrm{~mm} \text { small } \\
\text { fragement cancellous bone screw }\end{array}$ & $\begin{array}{l}\text { Usually available from } 30 \mathrm{~mm} \text { onwards } \\
\text { in } 5 \mathrm{~mm} \text { increment in length. }\end{array}$ \\
\hline
\end{tabular}

Table 2: Description of the screws used.

\begin{tabular}{|lllllllll|}
\hline $\begin{array}{l}\text { Size of } \\
\text { screw } \\
(\mathbf{m m})\end{array}$ & $\begin{array}{l}\text { Head } \\
\text { diameter } \\
(\mathbf{m m})\end{array}$ & $\begin{array}{l}\text { Recess } \\
(\mathbf{m m})\end{array}$ & $\begin{array}{l}\text { Thread length } \\
(\mathbf{m})\end{array}$ & $\begin{array}{l}\text { Thread } \\
\text { diameter } \\
(\mathbf{m m})\end{array}$ & $\begin{array}{l}\text { Shaft } \\
\text { diameter } \\
(\mathbf{m m})\end{array}$ & $\begin{array}{l}\text { Core } \\
\text { diameter } \\
(\mathbf{m m})\end{array}$ & $\begin{array}{l}\text { Drill bit for } \\
\text { thread hole } \\
(\mathbf{m m})\end{array}$ & $\begin{array}{l}\text { Tap } \\
\text { diameter } \\
(\mathbf{m m})\end{array}$ \\
\hline 6.5 & 8 & 3.5 & $16 / 32$ & 6.5 & 4.5 & 3.0 & 3.2 & 6.5 \\
\hline 4.0 & 6 & 2.5 & $16 / 32$ & 4.0 & 2.3 & 1.9 & 2.5 & 4.0 \\
\hline
\end{tabular}

These are cannulated, non-self tapping, partially threaded and used a lag screws. The partially threaded screw has thread length as $16 \mathrm{~mm}$ or $32 \mathrm{~mm}$. It is usually available in $5 \mathrm{~mm}$ increments, starting from $30 \mathrm{~mm}$ in length

Tapping of cancellous bone is unnecessary because the cancellous bone screw can easily cut a thread for itself. It's holding power is increased if its thread is not cut because it tends to compress, the trabeculae together when it is driven in.

The data was collected with the help of pre-validated case record proforma. The data is entered with the help of Microsoft Excel software. The data was tabulated for frequency distribution. 


\section{RESULTS}

The present study was conducted among 13 cases presented with tibial plateau fractures in department of Orthopedics in tertiary healthcare institute to evaluate the effect of a minimally invasive procedure for tibial plateau fractures through percutaneous fixation with cannulated screws and to study the risks connected with it. In the present study it was seen that tibial plateau fractures are more common in adults below 50 years, which is the most active period of life. The youngest patient in our series was 24 years old and oldest patient was 60 years old (Figure 1). Majority of our cases was males. Probably due to frequent exposure to high velocity injuries and trauma.

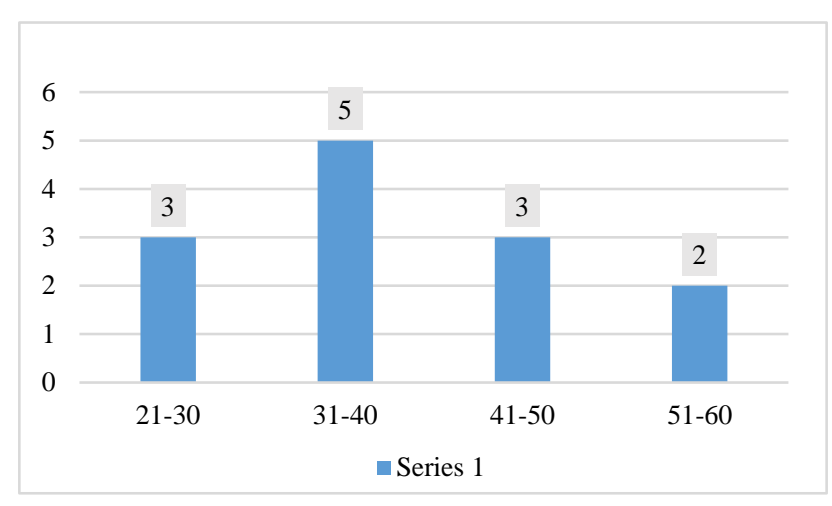

Figure 1: Age distribution of the cases.

Table 3: Closed and open fractures.

\begin{tabular}{|lll|}
\hline Nature of fractures & $\begin{array}{l}\text { No. of } \\
\text { cases }\end{array}$ & $\begin{array}{l}\text { Percentage } \\
(\%)\end{array}$ \\
\hline Closed & 12 & 93 \\
\hline Open & 1 & 7 \\
\hline Total & 13 & 100 \\
\hline
\end{tabular}

Table 4: Associated injuries.

\begin{tabular}{|lll|}
\hline Nature of injuries & $\begin{array}{l}\text { No. of } \\
\text { cases }\end{array}$ & $\begin{array}{l}\text { Percentage } \\
(\%)\end{array}$ \\
\hline Polytrauma & 2 & 16 \\
\hline Head injury & - & - \\
\hline $\begin{array}{l}\text { Minot injured or local } \\
\text { abrasions }\end{array}$ & 2 & 16 \\
\hline Compartment syndrome & 1 & 7 \\
\hline Nerve injuries & - & - \\
\hline
\end{tabular}

Closed fracture $(93 \%)$ was more common as compared to open fractures in our series (Table 3). The two patients (16\%) had associated bony injuries other than tibial condyles indicating the severity of violence. One patient (7\%) had compartment syndrome at the time of presentation. No patient in our series had early postoperative complication. One patient developed knee joint pain 16 months after operation due to early osteoartgritic changes. Most of the patients having isolated injuries were discharged after fifth postoperative day. Prolonged hospitalization required for patients having multiple injuries and associated complication compartment syndrome (Table 4 and 5).

Table 5: Postoperative complications.

\begin{tabular}{|lll|}
\hline Types of complication & No. of cases & $\begin{array}{l}\text { Percentage } \\
(\%)\end{array}$ \\
\hline Late & & \\
\hline Painful implant & 2 & 14 \\
\hline Traumatic arthritis & 1 & 7 \\
\hline
\end{tabular}

Table 6: Hospital stay.

\begin{tabular}{|llll|}
\hline No. of cases & Minimum & Maximum & A verage \\
\hline 13 & 5 days & 42 days & 10.46 \\
\hline
\end{tabular}

\section{DISCUSSION}

The knee joint is one the commonly injured joint. It is the largest and most complex joint, exposed to exterior. It helps in mobility and stability of the lower limb and hence locomotion. The functional capacity of any person depends on its integrity. The fractures around the knee joint are on an increase.

Fractures of the tibial condyles account for $1 \%$ of all fractures and $8 \%$ of the fractures in the elderly groups. The ideal outcome after a tibial plateau fracture is stable, pains-free, non-osteoarthritic knee joint with a range of motion that is adequate for functional requirements. There is virtual universal agreement that reduction and stabilization of displaced fragments, early mobilization and delayed weight-bearing are necessary to achieve an optimal result; however, controversy exists as to how these aims should be achieved. The debate is divided between two major groups, one favoring non-operative management and the other favoring operative treatment. Non-operative management and the other favoring operative treatment. Non-operative option includes traction and early mobilization, plaster cast immobilization and cast bracing while operative treatment usually comprises open reduction and buttress plating with bone grafting. ${ }^{9-11}$ Difficulties with conservative treatment include inadequate reduction, instability, prolonged hospitalization, knee stiffness, development of early osteoarthritic changes while open reduction and internal fixation is a difficult operation, even in experienced hands. It requires extensive exposure of the knee joint, compromise the soft tissues and devascularise the bone fragment. It is occasionally complicated by deep infection, wound dehiscence. ${ }^{11}$

Reduction by closed ligamentotaxis or assisted by arthroscopy and percutaneous fixation are methods that seek to combine the attributes of both operative and nonoperative philosophies while at the same time avoiding the complications of both. They have become feasible 
alternatives because use of image intensification and cannulated screws allows precise placement of the fixation device. Various studies have been done in the past regarding the tibial plateau fractures by M-Hohl, Apley, Rasmussen, Porter, Schatzker's and others to which we compared our results. ${ }^{12}$ Porter et al have studied only lateral plateau crush fracture (Compression or split compression); Dremann et al have studied central depression, split compression, bicondylar comminuted; Hohl has studied all types; Rasmussen et al have studied all fractures types; Schatzker's et al have studied all types. ${ }^{10,12,13}$

Our study is based on observations of 13 patients of tibial plateau fractures, Shatzker's type I to type IV, treated with closed reduction and percutaneous internal fixation with cannulated cancellous screws. However we did not came across with any case of Schatzker's type III tibial plateau fracture.

Hohl and Luc have studied 227 cases with follow-up of 2-13 years. Robert's 100 cases with follow-up of 2-12 years; Apley et al 60 cases with follow-up of 1-10 years; Rasmussen 204 cases with follow up of 4-11 years, Burn et al 278 cases, Duwelius et al cases. ${ }^{9,12,14}$ Our study includes 13 cases in a total period of 3 years in a prospective manner. We have analyzed the date in relation to age, sex, cause of injury, various types of fractures and compared and contrasted the result with other series.

In our series of 13 patients, only tibial plateau fractures Shatzkers type-I to type-IV was included. Split fractures $(38 \%)$ and mixed fracture $(38 \%)$ of lateral tibial plateau constituted majority of our cases. We did not come across with any case of Shatzker's type-III tibial plateau fracture, during our study period of 3 years.

In studies done by Rasmussen, Batalim and Wilpplula, Rinoapali lateral plateau fractures account for 55 to $70 \%$ medial plateau fractures 8 to $19.2 \%$ and bicondylar fractures accont for 18 to $31 \%$ the reason that lateral plateau fracture were common, is weaker trabecular pattern under the lateral condyle (as more weight transmission takes place through medial condyle) and frequent valgus injuries affecting the knee. As varus force is less common, medial plateau fracture is less. ${ }^{15}$

\section{Closed or open fractures}

13 cases of fresh fractures of tibial plateau, we encountered one $(7 \%)$ case of grade - I compound fracture. The wound was minimally contaminated. Thorough debridement done and washed with hydrogen peroxide and normal saline. It became healthy after 3 daily dressing, after that patient was operated for definitive fixation.

As our series is small and consisting of selected cases of tibial plateau fractures suitable for percutaneous fixation with cannulated cancellous screws, the Shatzker types fractures (close or open) cannot be compared with other series consisting of non selected cases. As the commonest cause of tibial plateau fractures are road traffic accident (high-energy trauma) significant number of cases were associated with multiple injuries at other sites. In Edwards et al series of 22 cases, 4 patients sustained multiple injuries.

In 13 patients of tibial plateau fractures treated by closed reduction and percutaneous internal fixation Keogh et al reported one case $(7 \%)$ of polytaruma and 3 cases $(23 \%)$ with minor injuries or local abrasion.

In present series of 13 patients there were 2 patients with polytrauma $(16 \%) ; 2$ patients with minor injuries or local abrasion at other sites (16\%) while one patient had compartment syndrome at the time of presentation $(7 \%)$. We observed that associated injuries have direct effect on early mobilization, total hospital stay and full weight bearing of the patient.

\section{Postoperative complications}

In present series, all cases were treated with closed reduction and percutaneous internal fixation with cannulated cancellous screws.

There was no early complication related to surgery such as superficial or deep infection, damage to neurovascular structures, deep vein thrombosis.

There was one case of Schatzker's type IV tibial plateau fracture with poor results. She had significant loss of fracture reduction, developed early osteoarthritis 16 months after trauma and knee joint pain affecting her daily activities. A total of 2 patients required removal of implant because of local discomfort after fracture had healed.

Keogh et al in their study of 13 cases treated by closed reduction and percutaneous internal fixation, reported no early complication in their patient except deep vein thrombosis in one patient with associated ipsilateral fracture femur. ${ }^{17}$ One patient had loss of reduction and one with mild to moderate pain 2 years after his fracture.

Edwards et al, in series of 22 operated cases by open reduction and internal fixation did not reported any major complications like neurovascular compromise, deep vein thrombosis or deep infections etc. But 4 cases had late complications, such as 1 patient had deep infection after 4 months, 1 patient had with loss of reduction with collapse of articular surface, 1 patient had anterior instability due to anterior cruciate and medial collateral ligament's damage, 1 patient developed condromalacia of medial femoral condyle. ${ }^{16}$

Keogh et al reviewed 46 cases of isolated tibial plateau fracture operated using AO techniques. They reported 
complications in 5 patients of which; 3 with superficial infection, one had reflex sympathetic dystrophy, another had persistent paresthesia on lateral calf and foot.

In their comparative study of conservative and operative treatment of tibial plateau fractures, Jensen et al, reported $12 \%$ complication rate in non-operated group as compared to $13 \%$ cases in operative group. Deep vein thrombosis $(4 \%)$ pneumonia $(4 \%)$, pin track infection $(4 \%)$ constitute majority of cases treated conservatively, while superficial wound infection $(5 \%)$ and deep vein thrombosis $(2 \%)$ constituted majority of cases treated surgically. ${ }^{18}$

\section{Hospital stays}

Most of the patients in our series having isolated tibial plateau fractures were discharged after first check dressing, usually on fifth postoperative day. Prolonged hospitalization of 6-7 weeks was required for 2 patients having multiple bony injuries and 1 patient with compartment syndrome. The average hospital stay required in our series was 10.46 day.

The study of 30 patients with cast brace for fracture of proximal tibia, George et al reported that, associated injuries or medical problems account for all hospitalization greater than 2 weeks, in their cases. ${ }^{19}$

Jensen et al studied a comparison of conservative and surgical treatment of tibial plateau fractures, their results suggests that prolonged hospitalization was needed for patient treated conservatively (avg. $=7$ weeks) as compared to patient treated operatively (avg. $=4$ weeks). ${ }^{18}$

\section{CONCLUSION}

13 cases of fresh tibial plateau fractures Shatzker's type-I to type IV in adults were analyzed and graded as excellent, good, fair and poor. The grading was done according to the Rasmussen's criteria.

The average duration of hospitalization was 10.46 days (range 5-42 days). The two patients with prolonged hospitalization (6-7 weeks) had multiple injuries. There was no early complication related to surgery like superficial or deep infection, damage to neurovascular structures, etc. ten patients $(76 \%)$ achieved full range of knee motion within 3 months after operation. All the fractures were united within 14 weeks duration.

Of the 13 patients, 12 had satisfactory results with no interference at work or recreational activities. One patient had a poor result 52 years old lady who had loss of reduction of a type IV fracture. Early osteoarthritic changes were apparent at 16 months after trauma and had knee joint pain affecting her daily activities. A total of two patients required removal of implant, after 1 year because of local discomfort after the fracture had healed.
No patient had angular deformity or instability at review and none required late surgery for internal derangement.

Funding: No funding sources

Conflict of interest: None declared

Ethical approval: The study was approved by the institutional ethics committee

\section{REFERENCES}

1. Cotton FJ, Berg R. Fender fractures of the tibia at the knee. N Engl J Med. 1929;201:989-95.

2. Marsh JL. Tibial plateau fractures. In: Bucholz RW, Heckman JD, Court-Brown CM, Tornetta P, McQueen MM, Ricci WM, editors. 7th ed. Philadelphia: Lippincott Williams \& Wilkins; 2010: 1780-1831.

3. Jacofsky DJ, Haidukerwych GJ. Insall \& Scott Surgery of the knee. Philadelphia: Churchill Livingstone; 2006. Tibia plateau fractures. In: Scott WN; 2006: 1133-1146.

4. Wang SQ, Gao YS, Wang JQ, Zhang CQ, Mei J, Rao ZT. Surgical approach for high-energy posterior tibial plateau fractures. Indian J Orthop. 2011;45(2):125-31.

5. Markhardt BK, Gross JM, Monu J. Schatzker Classification of Tibial Plateau Fractures: Use of CT and MR Imaging Improves Assessment. Radio Graphics. 2009;29:585-97.

6. Zeltser DW, Leopold SS. Classifications in brief: Schatzker classification of tibial plateau fractures. Clin Orthop Relat Res. 2013;471(2):371-4.

7. Dei Giudici L, Di Muzio F, Bottegoni C, Chillemi C, Gigante A. The role of arthroscopy in articular fracture management: the lower limb. Eur J Orthop Surg Traumatol. 2015;25(5):807-13.

8. Mittal R, Banerjee S. Proximal femoral fractures: Principles of management and review of literature. J Clin Orthop Trauma. 2012;3(1):15-23.

9. Apley GA. Fracture of the tibial plateau, Orthop Clin North Am. 1979;10:61-74.

10. Drennan DB, Locher FG, Maylahn DJ. Fractures of the tibial plateau: Treatment by closed reduction cast. J Bone Joint Surg. 1979;61:989-95.

11. Schatzker J, McBroom R, Bruce D. The tibial plateau fracture, the Toronto experience. Clin Orthop Relat Res. 1979;(138):94-104.

12. Hohl M. Tibial condylar fractures. JBJS. 1967;49(7):1455-67.

13. Porter BB. Crush fracture of lateral tibial condlye. J. Bone Joint Surg. 1970;52:676-87.

14. Duwelius PJ, Connelly JF. Closed reduction of tibial plateau fracture: A comparison of functional and roentgenographic end results. Clin Ortop. 1968;230:116-26.

15. Duparc F. Fracture of the tibial plateau in Insall. Surgery of the knee 2nd edition. Volume 2. New York, Churchill Livingstone; 1995: 1074..

16. Edwards ER, Chin TYP, Bardana D, Bailey M, Williamson OD, Miller R, et al. Func-tional 
outcome of tibial plateau fractures treated with the fine-wire fixator. Injury. 2005;36(12):1467-75.

17. Keogh P, Kelly C, Cashman WF, McGuinness AJ, O'Rourke SK. Percutaneous screw fixation of tibial plateau fractures, Injury. 1992;23(6):387-9.

18. Jensen DB, Rude C, Duus B, Bjerg-Nielsen A. Tibial plateau fractures. A comparison of conservative and surgical treatment. J Bone Joint Surg Br. 1990;72(1):49-52.

19. Babis GC, Evangelopoulos DS, Kontovazenitis P, Nikolopoulos K, Soucacos PN. High energy tibial plateau fractures treated with hybrid external fixation. J Orthop Surg Res. 2011;6:35.

Cite this article as: Bagul JP, Dole PP. Assessment of the complications after percutaneous fixation with cannulated cancecellous screws among the cases of tibial plateau fractures in a tertiary healthcare institute: a cross sectional study. Int J Res Orthop 2020;6:327-32. 